\title{
HOW CAN WE PREDICT DIABETES RESOLUTION AFTER METABOLIC SURGERY?
}

Authors: IZABELA KARPIŃSKA ${ }^{1}$, JOANNA CHOMA ${ }^{1}$, ALICJA DUDEK ${ }^{1}$, PIOTR MAŁCZAK ${ }^{1}$ (mentor), MAGDALENA SZOPA ${ }^{2}$ (mentor), PIOTR MAJOR ${ }^{1}$ (mentor)

${ }^{1} 2^{\text {ND }}$ DEPARTMENT OF GENERAL SURGERY, JAGIELLONIAN UNIVERSITY MEDICAL COLLEGE, KRAKÓW, POLAND

${ }^{2}$ DEPARTMENT OF METABOLIC DISEASES, JAGIELLONIAN UNIVERSITY MEDICAL COLLEGE, KRAKÓW, POLAND

DOI: https://doi.org/10.26800/LV-142-supp5-52

\section{Introduction:}

Bariatric surgery is efficient treatment of type 2 diabetes mellitus (T2DM). Despite detailed qualification, not every patient achieve T2DM remission. Individualised Metabolic Surgery (IMS) and DiaRem scores have been recently developed to predict diabetes remission after bariatric surgery.

\section{Aim:}

To validate and compare the performance of IMS and DiaRem scores as the predictors of diabetes remission 1 year after surgical treatment.

\section{Materials \& methods:}

The retrospective analysis included patients with T2DM who underwent Roux-en-Y gastric bypass (RYGB) or sleeve gastrectomy (SG) and completed 1-year follow-up. IMS and DiaRem scores were calculated for each patient. Each score relationship with diabetes remission was assessed using logistic regression. Discrimination was evaluated by area under the receiver operating characteristic curve (AUROC) whereas calibration by Hosmer-Lemeshow test.

\section{Results:}

Out of 252 patients in our study 150 (59.5\%) were women whereas 102 (40.5\%) were men with median age 48 years. $46.83 \%$ underwent SG whereas $53.17 \%$ had RYGB. The T2DM remission rate reached $90.5 \%$. Median of preoperative A1c was $6.75 \%$ and preoperative BMI was $45.39 \mathrm{~kg} / \mathrm{m} 2$, both decreased to $5.8 \%$ and $33.09 \mathrm{~kg} / \mathrm{m} 2$ after 1 year. \%EWL after surgery was $53.4 \%$. Either IMS or DiaRem were predictive of diabetes remission in a logistic regression analysis (OR 0.97; $p<0.0001 ;$ OR 0.83; $p<0.0001$ ). Both scores demonstrated acceptable discrimination (AUROC 0.76; $p<0.0001 ; A U R O C$ 0.78; $p<0.0001)$. Only DiaRem score presented good calibration.

\section{Conclusion:}

Both IMS and DiaRem scores can be used in preoperative assessment of bariatric patients, but DiaRem score is more accurate than IMS.

Keywords: Diabetes remission, External validation, Metabolic surgery, Risk prediction scores, Type 2 diabetes mellitus 